\title{
EXPERIMENTAL IDENTIFICATION OF A SERVO-VALVE PARAMETERS USED FOR AN ELECTRO-HYdRAUlic SERVo-ACTUATOR DEVELOPMENT
}

\author{
DINCA L. \& CORCAU J. I.
}

Abstract: In this paper ones followed to obtain a simplified mathematical model for an electro-hydraulic servo-valve and further to identify the parameters defined in this model, in order to use it in an electro-hydraulic servo-actuator development. The mathematical model concern only the stationary behavior of the servo-valve. There are briefly presented the schemes of the hydraulic test bench used in the laboratory, it is obtained the mathematical model of the servo-valve and there are determined the parameters involved in the mathematical model. The mathematical model uses some global parameters of the open center servo-valve used on the hydraulic test bench. Ones aimed to define some parameters which are easy to be identified and are enough representatives in the development process of a servo-actuator.

Key words: servo-valve; experimental development; numerical simulation; electrohydraulic servo-actuator, experimental results
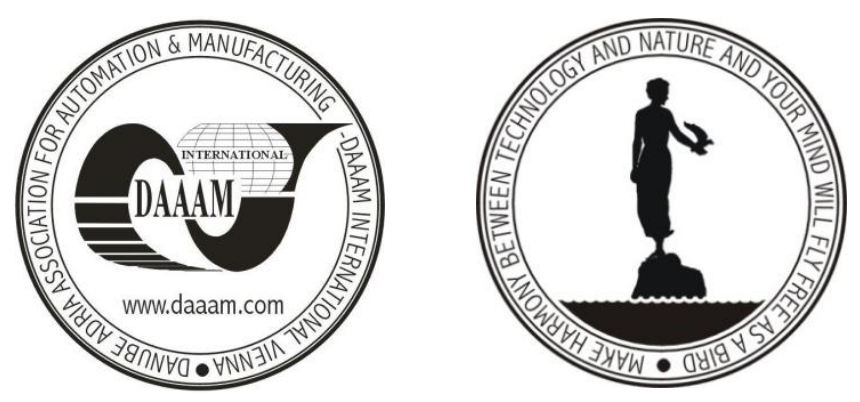

Authors' data: Associate Professor PhD. Dinca, L[iviu]; Senior Lecturer $\mathrm{PhD}$. Corcau, J[enica] Ileana, University of Craiova, Decebal, 107, Romania, ldinca@elth.ucv.ro, jcorcau@elth.ucv.ro

This Publication has to be referred as: Dinca L[iviu] \& Corcau,J[enica] [I]leana (2013) Experimental Identification of a Servo-Valve Parameters Used for an ElectroHydraulic Servo-Actuator Development, Chapter 49 in DAAAM International Scientific Book 2013, pp. 813-830, B. Katalinic \& Z. Tekic (Eds.), Published by DAAAM International, ISBN 978-3-901509-94-0, ISSN 1726-9687, Vienna, Austria DOI: $10.2507 /$ daaam.scibook.2013.49 


\section{Introduction. Hydraulic Test Bench Scheme}

Hydraulic servo-valves testing was in the past, and is in present keen interest. Both the producers and the research laboratories followed to develop test facilities in order to identify the most important servo-valve parameters. In (Tootell et. al., 1990) is presented one such bench developed at ' 90 level. The signal conditioning and data acquisition system was performed by electronic specialized equipment development. In (Dinca et. al., 2010) is developed a multifunctional test bench realized under one of the authors coordination. This new test bench uses the advantages of the modern data acquisition systems and the computer data processing. The necessary electrical signals were acquired by a NI-USB 6251 data acquisition board and the processing was performed using LabView and MATLAB/SIMULINK.

The hydraulic bench built (figure 1) was presented in full in (Dinca et. al., 2010) and is composed from an electro-distributor (D), used for the fast hydraulic feeding cut in emergency situations, a filter $(\mathrm{F})$ with the roughness of $5 \mu \mathrm{m}$, to ensure the hydraulic liquid quality at the servo-valve input, an electro-hydraulic servo-valve DY-05 produced by Parker-Hannifin with the nominal flow rate $9.51 / \mathrm{min}$ at 69 bar (1000 psi) pressure drop on the servo-valve, four pressure transducers (TP1 - TP4), two taps (R1 and R2), four unidirectional valves (S1 $-\mathrm{S} 4)$, a flow ratio transducer (TD) and a hydraulic cylinder (CH).

In figure 2 are shown the control panel of the bench (fig. 2.a) and the laptop and data acquisition card used for the servo-valve characteristics processing (fig. 2.b). On the laptop screen one observe the control panel of the LabView data acquisition scheme.

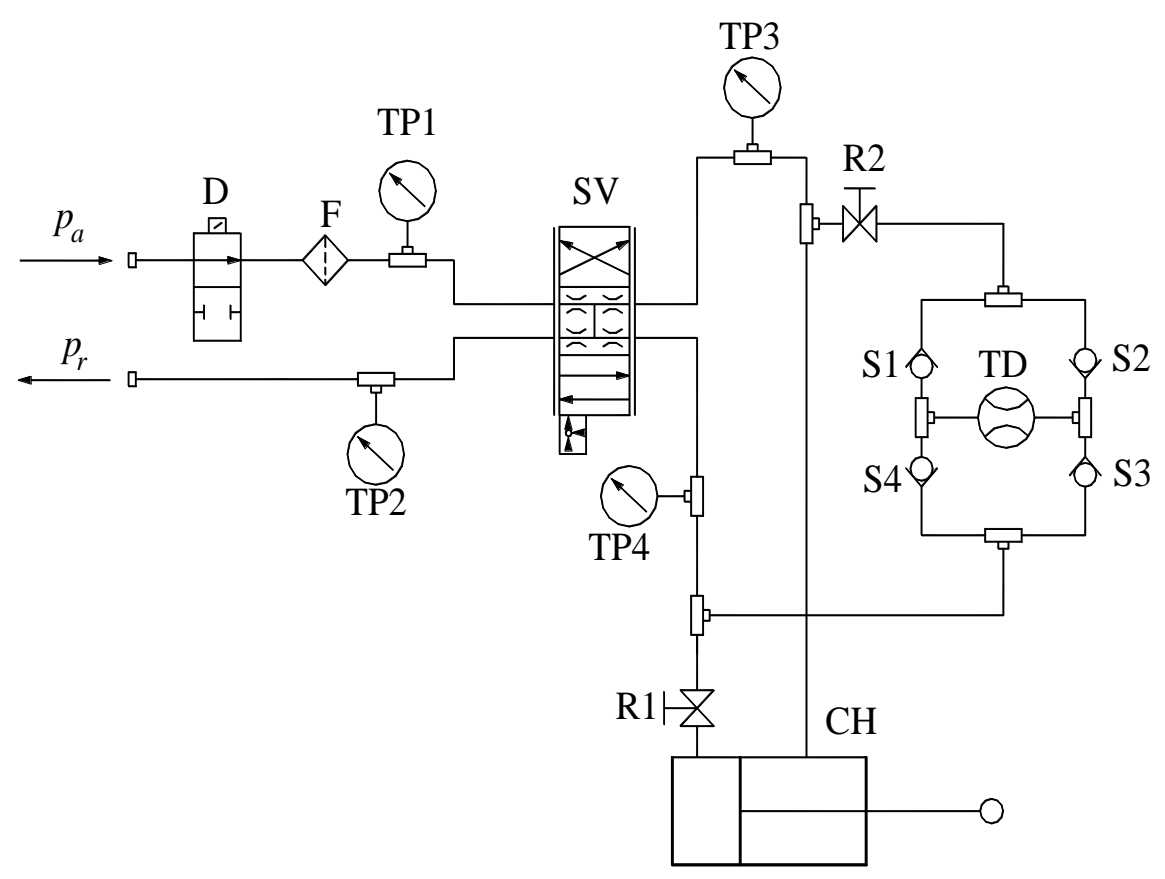

Fig. 1. Hydraulic test bench scheme 
The hydraulic scheme was designed so that it is possible to study both servovalves and servo-actuators on the same test bench. The servo-actuators can be realized with many different kinds of controllers.

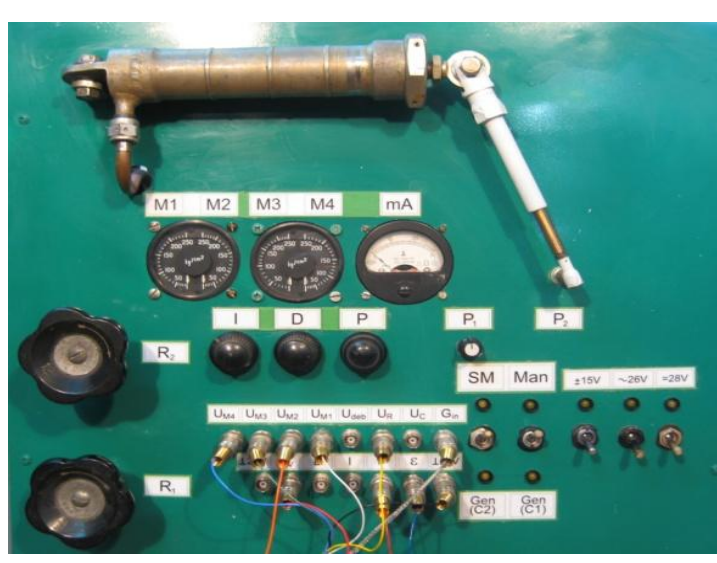

a)

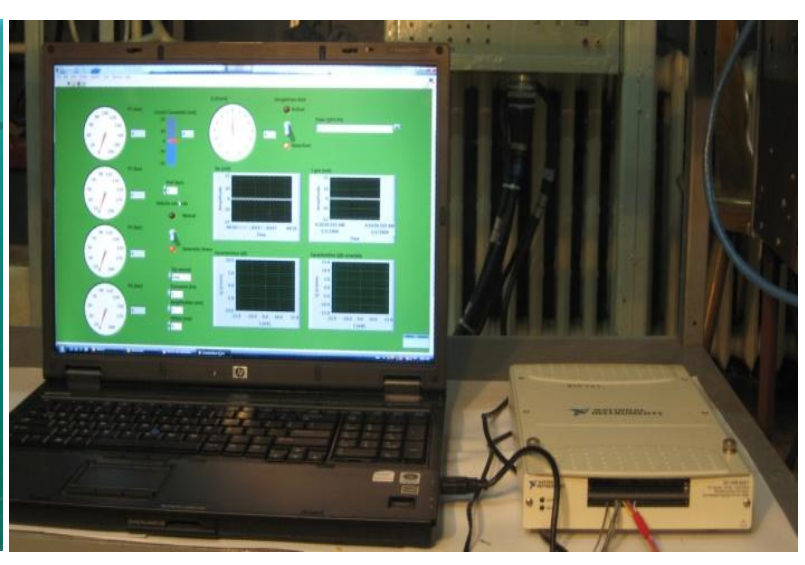

b)

Fig. 2. Experimental system used in laboratory

In order to outline the servo-valve characteristics, the tap R1 is closed and the tap R2 is opened. So, the hydraulic cylinder is out of circuit and one can measure the servo-valve ports pressures and the flow ratio through the circuit. After the outlining the servo-valve characteristics the tap R2 is closed and the tap R1 is opened. In this manner, the flow ratio measurement system is cut out to the circuit and the hydraulic cylinder is put in. Together with the electronic command system, the servo-valve (SV) and the hydraulic cylinder $(\mathrm{CH})$ forms a servo-actuator which can be studied experimentally. Electrical scheme (fig. 3) of the bench was also presented in full in (Dinca et. al., 2010).

Like the hydraulic scheme, the electric scheme is also designed so that it permits to study both the servo-valve characteristics and the behavior of the servo-actuators provided with different kinds of controllers. The central element of the electric scheme is the electro-hydraulic servo-valve.

Its electrical winding are fed from a voltage-current converter which receive the command voltage either from an analog controller embedded in the test bench, either from the outside of the bench by the $\mathrm{G}_{\text {in }}$ terminal. By this way ones may reach the both aims - servo-valve study or servo-actuator study. The voltage-current converter is equipped with a current transducer which permits to acquire the current value with a data acquisition card. The servo-valve command current may also be read by a mili$\operatorname{ammeter}(\mathrm{mA})$.

In order to outline the servo-valve characteristics the switch $\mathrm{C} 1$ in placed in position 1 and the switch $\mathrm{C} 2$ is placed in position 2 (like in figure 3). The signals used for the $Q=f(I)$ servo-valve characteristic outline are the pressures $p_{1}-p_{4}$, the flow ratio $Q$ and the command current $I$. The pressures $p_{1}-p_{4}$, are necessary to bring the characteristic to the standard testing conditions. The bench does not create the 
standard testing conditions for the servo-valve, but the acquired data may be corrected using the pressures $p_{1}-p_{4}$.

When a servo-actuator is studied, there are some possibilities. Once, it can be used the analog embedded controller. The coefficients of the controller may be adjusted by the potentiometers P, I, D. In this case the switch C2 is placed on the position 1 and the voltage-current converter receives the input from the adder SUM2. The proportional, derivative and integrator controllers receive as inputs the error signal from the adder SUM1. This adder make the difference between the command voltage $U_{C}$ and the feedback voltage $U_{R}$.

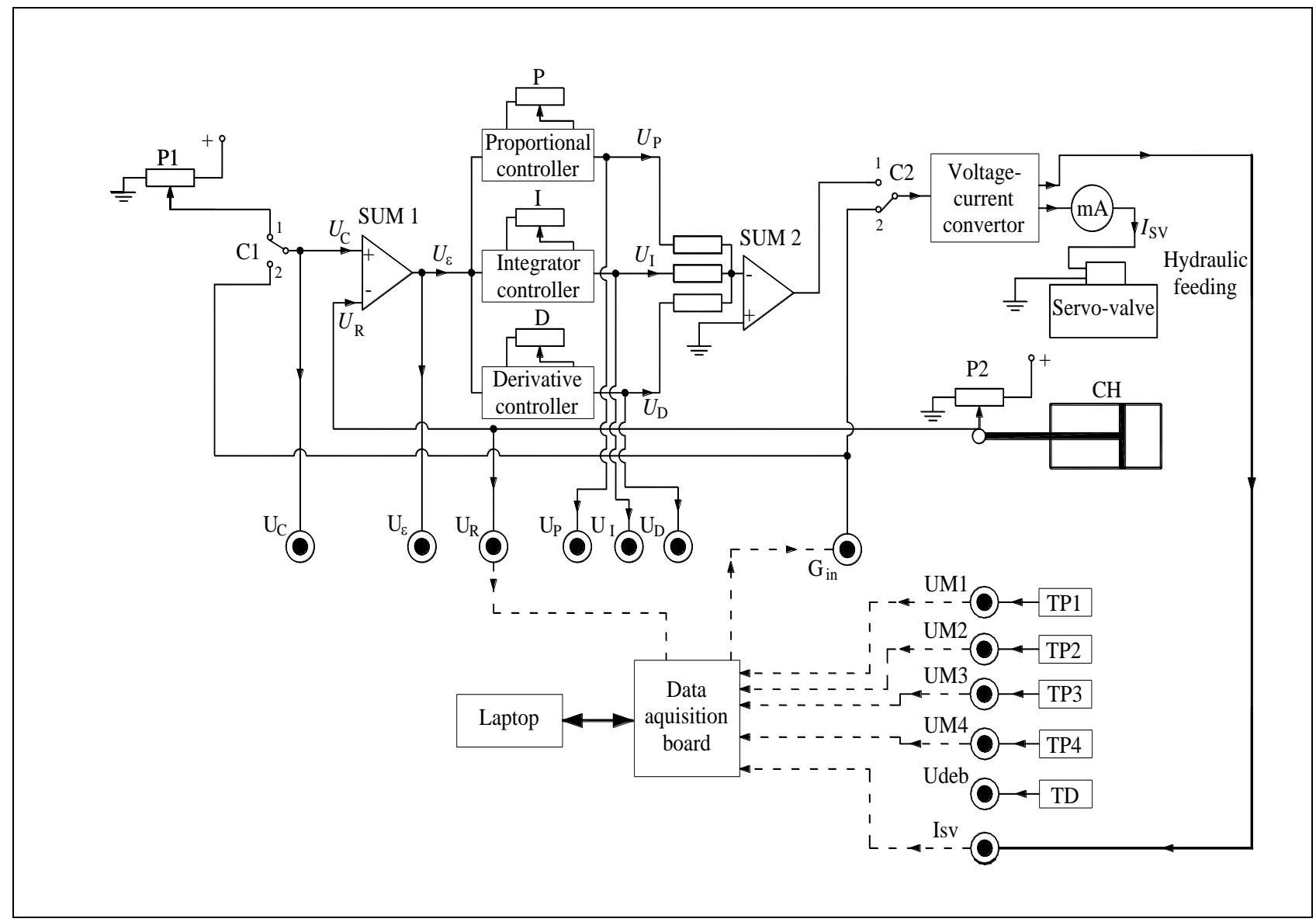

Fig. 3. Electrical scheme of the hydraulic test bench

The command voltage may be obtained either from potentiometer P1 when the switch $\mathrm{C} 1$ is placed on the position 1, either from the input terminal $\mathrm{G}_{\text {in }}$ when the switch $\mathrm{C} 1$ is on the position 2 . The voltages $U_{C}, U_{R}, U_{\varepsilon}$ and the outputs from the analog controllers $U_{P}, U_{I}, U_{D}$ are available on the control panel at the corresponding terminals. These voltages may be acquired with a data acquisition board in order to process its with a laptop.

If it is desired to study a more complex controller, implemented on a laptop, the feedback voltage $U_{R}$ is used and the command signal is generated by the laptop. The switch $\mathrm{C} 1$ is in position 1 and the switch $\mathrm{C} 2$ is in position 2 . The both signals are processed by the control algorithm and the controller output is applied by the data acquisition card to the terminal $\mathrm{G}_{\mathrm{in}}$. In this manner, the controller implemented on the laptop commands the voltage-current converter. The control loop is closed by the $U_{R}$ 
voltage and the laptop implemented controller. All the necessary signals are processed and may be shown on the laptop.

\section{Mathematical Modeling and Experimental Identification of the Servo-Valve}

Mathematical modeling of the servo-valves and numerical simulation of their functioning is also a large interest domain in the field of the hydraulic command equipments study. In (Cheng et. al., 2006), (Borello et. al., 2009), (Dean et. al., 2000), (Tao et. al., 2005), (Grodić et. a1., 2004), (Kim \& Tsao, 2000), (Ruan et. al., 2000), (Li et. al., 2009), (Chen \& Stoffel, 2004) are presented many studies concerning the mathematical modeling of the electro-hydraulic servo-valves taking account of different details like the elasticity of the torque motor components, the turbulence, the cavitation in the hydraulic flow, the use of piezo-electric actuators for the first stage distributor, etc.

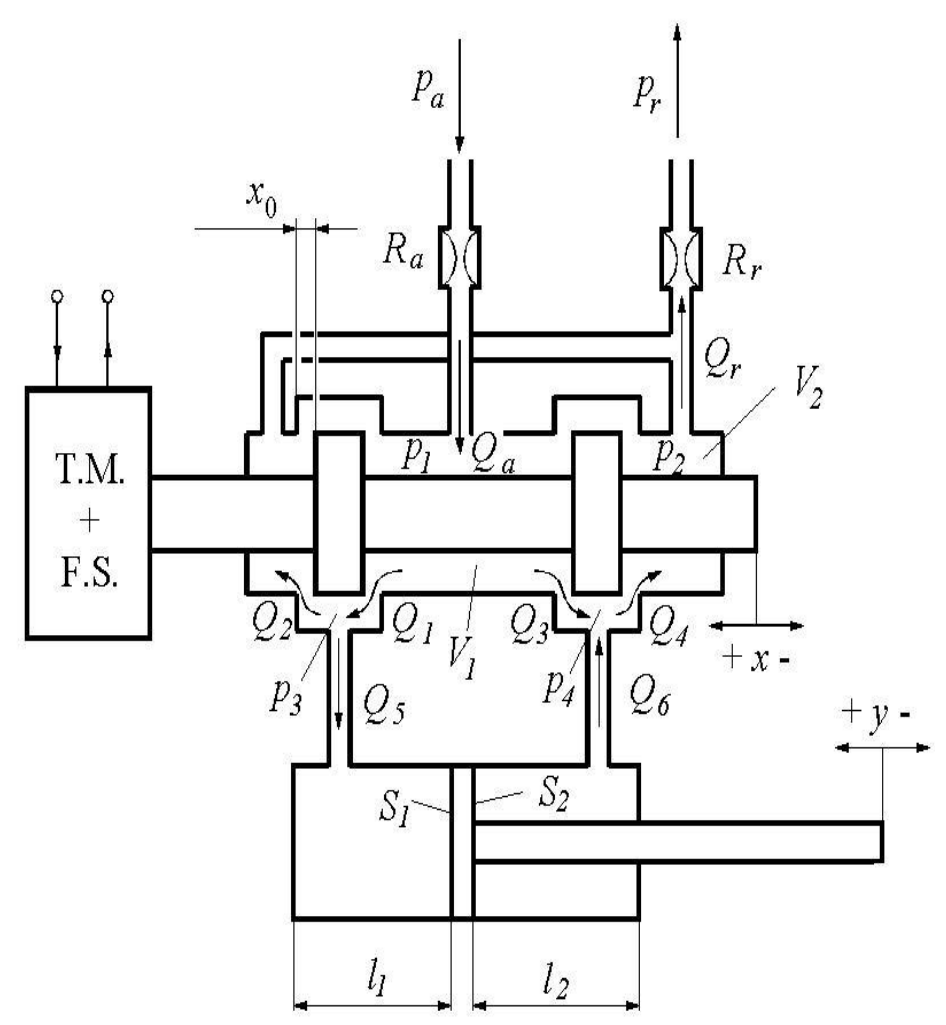

Fig. 4. The model of the final stage of the servo-valve

These are models used in order to improve the design of the future electrohydraulic servo-valves. Such studies are found also in (Urata, 1999), (Zhang et. al. , 2003), (Kiliç, \& Kapucu, 2011), (Karunanidhi \& Singaperumal, 2010), (Prodan et. al., 2011). But for usual studies concerning the hydraulic installations functioning, it is difficult to use these models. It may be preferable to use more simplified models with the same results concerning the entire installation functioning. The gain in precision is negligible with respect the computational volume needed. 
In this paper one follow to simplify the problem in order to obtain easy to use relations in usual applications. One start from the supposition that the 90 degrees frequency of the modern servo-valves is considerably higher than the frequency needed in usual actuations, like the vehicles steering systems. Response times of 11 ms permit to consider a proportional behavior of the servo-valve in these systems. Difficult problems may appear in the aircraft command surfaces actuations where the appearance of the buzz-flutter phenomenon with frequencies about tens of hertz may lead to the actuation system instability and in this case, the dynamical behavior of the servo-valve is necessary to be taken account.

Taking account the short response time of the servo-valve (see DY05 ParkerHannifin catalog) one may consider the servo-valve composed from the torque motor (T.M. in figure 4) and the first hydraulic stage (F.S. in figure 4). For these elements one may consider a proportional dependence between the command current $i$ and the displacement $x$ of the second hydraulic stage spool. For the second hydraulic stage, taking account is an open center servo-valve, one may consider the model in figure 4.

The spool of the second hydraulic stage has negative covering and in figure 4 appear two additional hydraulic resistances, one on the feeding pipe $R_{a}$, and one on the return pipe $R_{r}$. These resistances appear because the distance between the pump and hydraulic bench is relative great (about $3 \mathrm{~m}$ ) and the pipes have a small diameter (about $5 \mathrm{~mm}$ ). The same is the situation with the return pipe. In the aircraft hydraulic systems the distance between the pump and the servo-actuator is about tens meters. In this case the pipes hydraulic resistance is not negligible any more.

As we mentioned before, we consider a proportional dependence between the command current $i$ and the spool displacement $x$. Following figure 4 one may deduce the following equations which describe the second hydraulic stage functioning.

$$
\begin{gathered}
x=k \cdot i \\
Q_{1}=\mu_{d} \cdot L \cdot\left(x_{0}+x\right) \cdot \sqrt{\frac{2}{\rho}} \cdot \sqrt{p_{1}-p_{3}}=\mu_{d} \cdot L\left(x_{0}+k \cdot i\right) \cdot \sqrt{\frac{2}{\rho}} \cdot \sqrt{p_{1}-p_{3}}= \\
=(a+b \cdot i) \cdot \sqrt{p_{1}-p_{3}}, \\
Q_{2}=\mu_{d} \cdot L \cdot\left(x_{0}-x\right) \cdot \sqrt{\frac{2}{\rho}} \cdot \sqrt{p_{3}-p_{2}}=(a-b \cdot i) \cdot \sqrt{p_{3}-p_{2}}, \\
Q_{3}=\mu_{d} \cdot L \cdot\left(x_{0}-x\right) \cdot \sqrt{\frac{2}{\rho}} \cdot \sqrt{p_{1}-p_{4}}=(a-b \cdot i) \cdot \sqrt{p_{1}-p_{4}}, \\
Q_{4}=\mu_{d} \cdot L \cdot\left(x_{0}+x\right) \cdot \sqrt{\frac{2}{\rho}} \cdot \sqrt{p_{4}-p_{2}}=(a+b \cdot i) \cdot \sqrt{p_{4}-p_{2}}, \\
Q_{5}=Q_{1}-Q_{2}, \\
Q_{6}=Q_{4}-Q_{3}, \\
Q_{a}=Q_{1}+Q_{3},
\end{gathered}
$$




$$
\begin{gathered}
Q_{r}=Q_{2}+Q_{4}, \\
a=\mu_{d} \cdot L \cdot x_{0} \cdot \sqrt{\frac{2}{\rho},} \\
b=\mu_{d} \cdot L \cdot k \cdot \sqrt{\frac{2}{\rho}},
\end{gathered}
$$

In equations (2) - (5) the distance $x_{0}$ represents the opening of the final distributor when the spool is in the neutral position. Because it is difficult to identify each parameter (the low coefficient $\mu_{d}$, the openings length $L$, the opening in the neutral point $x_{0}$, and the proportionality coefficient between the command current and the spool displacement $x$ ), we grouped these terms in two parameters, $a$ and $b$, which can be easier identified experimentally, so that one obtain a mathematical model with numerical values as closer as possible to the reality.

From relations (2) - (9) one may obtain the load flow rates $Q_{5}$ and $Q_{6}$, as it follows:

$$
\begin{aligned}
& Q_{5}=(a+b \cdot i) \cdot \sqrt{p_{1}-p_{3}}-(a-b \cdot i) \cdot \sqrt{p_{3}-p_{2}}, \\
& Q_{6}=(a+b \cdot i) \cdot \sqrt{p_{4}-p_{2}}-(a-b \cdot i) \cdot \sqrt{p_{1}-p_{4}} .
\end{aligned}
$$

But in the servo-actuator functioning, at big command current, two of the final distributor opening reach to zero, so if $i>I_{c l}$ one obtain

$$
\begin{aligned}
& Q_{5}=Q_{1}=(a+b \cdot i) \cdot \sqrt{p_{1}-p_{3}}, \\
& Q_{6}=Q_{4}=(a+b \cdot i) \cdot \sqrt{p_{4}-p_{2}},
\end{aligned}
$$

and if $i<-I_{c l}$,

$$
\begin{aligned}
Q_{5}=Q_{2} & =-(a-b \cdot i) \cdot \sqrt{\left|p_{3}-p_{2}\right|}, \\
Q_{6} & =Q_{4}=-(a-b \cdot i) \cdot \sqrt{\left|p_{1}-p_{4}\right|} .
\end{aligned}
$$

In relations (14) $-(17), I_{c l}=a / b$. If $i<-I_{c l}$, the flows $Q_{5}$ and $Q_{6}$ change the direction with respect the figure 4 .

In order to identify the parameters $a$ and $b$ we used the hydraulic bench presented before, closing the tap R1 and opening the tap R2. The liquid from the servo-valve will flow through the valves bridge S1 - S4 and the flow ratio transducer TD. So, the flows $Q_{5}$ and $Q_{6}$ will be equal. Measuring the command current $i$ and the servo-valve flow $Q_{5}=Q_{6}$ one may outline the characteristic $Q=f(I)$. But the used hydraulic test bench has a difference big enough with respect the standard conditions 
for the servo-valves testing. In standard testing conditions the servo-valve ports to the load are short-circuited. On the test bench, the valves bridge and the pipes between these ports have a relative high and unknown hydraulic resistance. So, the obtained characteristic $Q=f(I)$ has to be corrected with respect these hydraulic resistances. Although, in standard conditions it is specified a pressure drop on the servo-valve of 69 bar (1000 psi), that means it has to be made another correction with respect the servo-valve pressure drop.

For the standard conditions, the characteristic $Q=f(I)$, from equations (12) and (13) results like in figure 5, "Theoretical characteristic" - curve.

The shape in figure 5 corresponds with the specifications in (http://www.moog.com). Near the origin the slope is double with respect the slope after $I_{c l}$. In (http://www.moog.com) one specify that near origin the slope may vary between $b / 2$ and $2 b$, but it is not specified if the servo-valve has open center or close center. For closed center servo-valves, it is possible to differ the slope near origin from the value $2 b$.

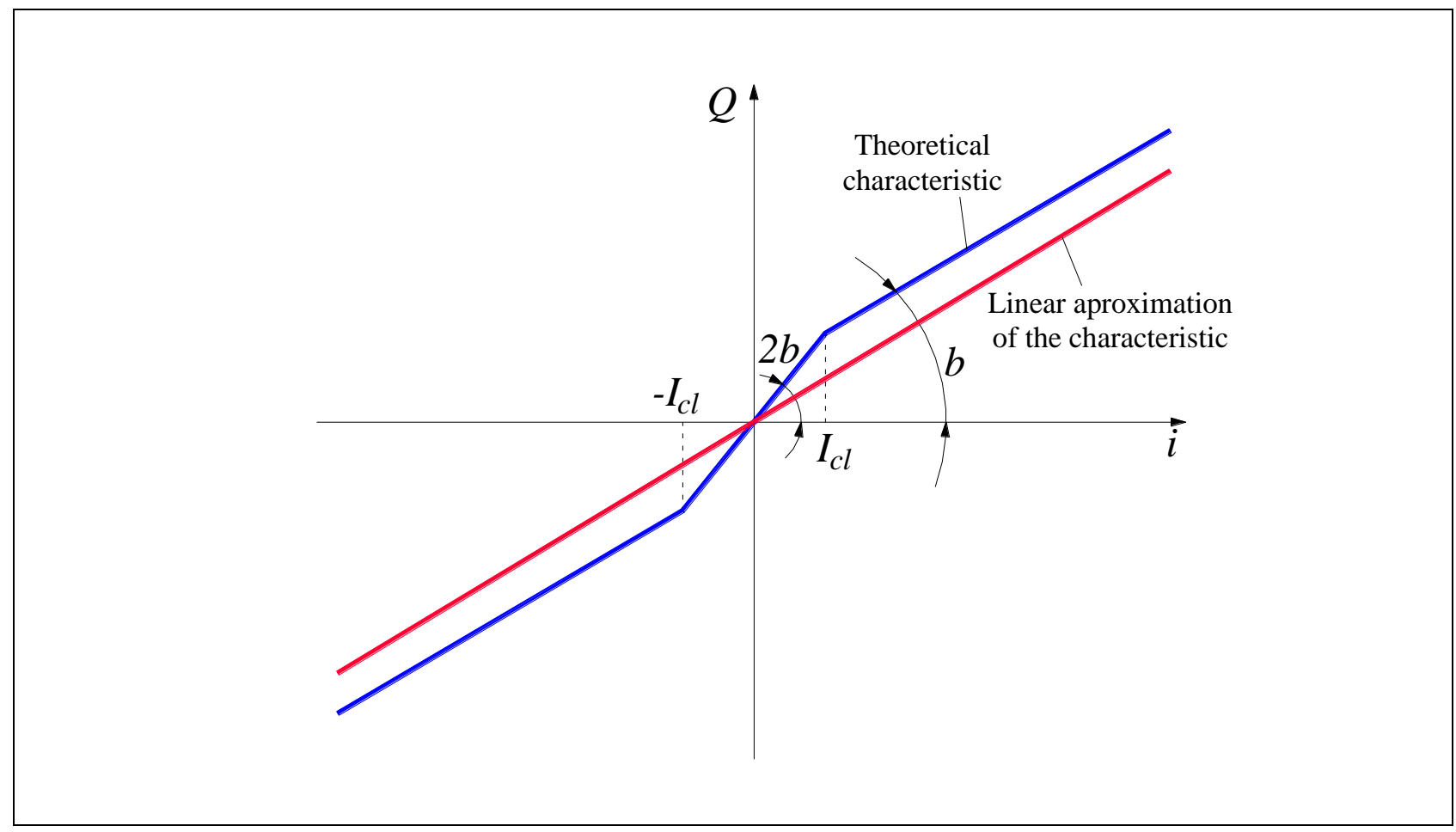

Fig. 5. Theoretical characteristic $Q=f(I)$

Because the current $I_{c l}$ is small, the characteristic may be approximated with the straight line - "Linear approximation of the characteristic". This approximation is useful because on the test bench it is not possible to measure the slope near origin because the valves S1 - S4 have a opening pressure about $2-3$ bar and so, the small current region of the characteristics is lost.

In order to make the corrections with respect the servo-valve drop pressure and the load hydraulic resistance, we considered the equivalent hydraulic scheme in figure 6 . 


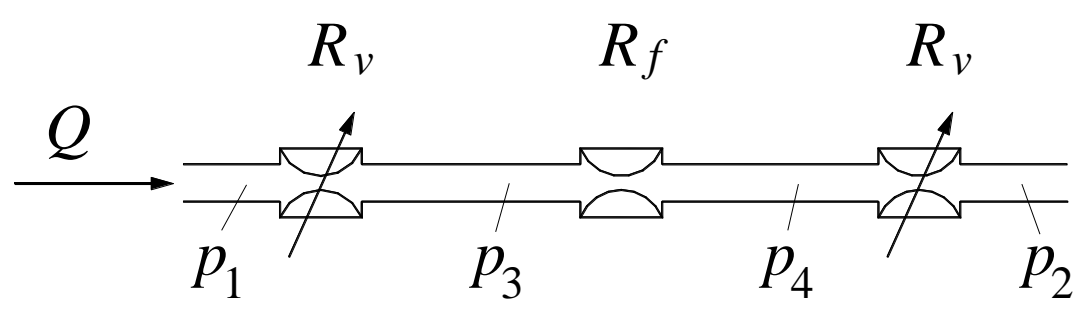

Fig. 6. Equivalent hydraulic scheme of the servo-valve

The scheme in figure 6 take account the situation when the command current $i$ exceeds the value $I_{c l}$ and the load ports are linked through the resistance $R_{f}$. So, one may write the relations:

$$
\begin{gathered}
p_{1}-p_{3}=R_{v} \cdot Q^{2} \\
p_{3}-p_{4}=R_{f} \cdot Q^{2}, \\
p_{4}-p_{2}=R_{v} \cdot Q^{2} .
\end{gathered}
$$

As it is observed from figure 1 , it is possible to measure the pressures $p_{1}-p_{4}$, the flow ratio $Q$, and from figure 2 it is possible to measure the command current $i$. It is necessary to determine de flow ratio $Q$ at $R_{f}=0$ and $p_{1}-p_{2}=p_{\text {ref }}=69$ bar, when the measured parameters are specified before. From relations (18) - (20) results

$$
\begin{gathered}
p_{1}-p_{2}=\left(2 R_{v}+R_{f}\right) \cdot Q^{2} \\
p_{3}-p_{4}=R_{f} \cdot Q^{2}
\end{gathered}
$$

So,

$$
2 \cdot R_{v}=\frac{\left(p_{1}-p_{2}\right)-\left(p_{3}-p_{4}\right)}{Q^{2}}
$$

If $R_{f}=0$ then $p_{3}=p_{4}$ and

$$
p_{1}-p_{3}=p_{3}-p_{2}=R_{v} Q_{\text {corrected }}^{2}
$$

From the first part of relation (24) results

$$
p_{3}=\frac{p_{1}+p_{2}}{2}
$$

which replaced in the second part of the equation (24) reach to 


$$
p_{1}-p_{2}=2 \cdot R_{v} \cdot Q_{\text {corrected }}^{2}
$$

In (24) it must make although the correction with respect the servo-valve pressure drop, so one will consider $p_{1}-p_{2}=p_{\text {ref }}$ and

$$
\frac{p_{r e f}}{2 \cdot R_{v}}=\frac{p_{r e f}}{\left(p_{1}-p_{2}\right)-\left(p_{3}-p_{4}\right)} Q^{2}=Q_{\text {corrected }}^{2}
$$

or

$$
Q_{\text {corrected }}=Q \sqrt{\frac{p_{\text {ref }}}{\left(p_{1}-p_{2}\right)-\left(p_{3}-p_{4}\right)}}
$$

In conclusion, in order to correct the flow ratio indicated by the flow transducer TD with respect the hydraulic resistance $R_{f}$ and the servo-valve pressure drop we used the relation (28). By this way, the flow ratio is brought to standard conditions.

Because in standard conditions $p_{3}=p_{4}$ and $Q_{5}=Q_{6}$ results the relation (25), which used in (14) one obtain

$$
Q_{5}=Q_{\text {corrected }}=(a+b \cdot i) \sqrt{\frac{p_{1}-p_{2}}{2}}=(a+b \cdot i) \sqrt{\frac{p_{r e f}}{2}} .
$$

In figure 5, the linear approximation slope is equal with the theoretical characteristic slope for $i>I_{c l}$, so, one may approximate the characteristic with

$$
Q_{\text {aproximatel }}=b \cdot i \cdot \sqrt{\frac{p_{r e f}}{2}},
$$

which is a straight line with the slope

$$
S_{c}=b \sqrt{\frac{p_{r e f}}{2}}
$$

In conclusion, if one approximate the servo-valve characteristic with a straight line and determine experimentally its slope, one may obtain the parameter $b$.

The experimental data obtained and corrected according to (28) are presented in figure 7 in red color. With blue color is represented the line which has the best least squares approximation of the experimental data and with green color is the line with the slope given by (31). 
One observes the linear approximation of the characteristic does not reach the origin, so there is a bias current. The null flow ratio is obtained at $i_{\text {bias }}=2.827 \mathrm{~mA}$. Taking account the reference pressure $p_{\text {ref }}=69 \mathrm{bar}$, after data processing, the parameter $b$ value resulted $b=0,0600 \mathrm{l} /(\mathrm{min} \cdot \mathrm{mA} \cdot \sqrt{\mathrm{bar}})$.

From figure 7 one observe a nonlinearity of the experimental characteristic. In the catalog page of the DY05 servo-valve it is specified a non-linearity less than $10 \%$, which is an usual value for hydraulic equipment but big enough for an equipment with a good linearity.

The torque motor windings were series connected in the electric scheme. Although the maximum admitted command current in this configuration is $25 \mathrm{~mA}$, the electronic scheme of the hydraulic bench limits the current at $\pm 19,5 \mathrm{~mA}$, so the experimental data correspond to this interval. The data near origin were excluded because in this interval the valves S1-S4 are closed.

In order to determine the parameter $a$ one used the stationary regime of the a servo-actuator. The laboratory realized servo-actuator used a unilateral-rod cylinder. The piston diameter is $30 \mathrm{~mm}$ and the rod diameter is $14 \mathrm{~mm}$. Due to the hydraulic cylinder asymmetry the rest position of the piston will be obtained when pressures $p_{3}$ and $p_{4}$ satisfy the relationship

$$
p_{3 r} \cdot S_{3}=p_{4 r} \cdot S_{4}
$$

This situation produces the necessity of a small current through the servo-valve windings when the piston is at rest. The rest position is not obtained at null current. Measuring this current and taking account of the bias current one can determine the parameter $a$. The rest current is small and will be in the interval $\pm I_{c l}$, so, for the flows calculus one use the relations (12) and (13) and impose the condition $Q_{5}=Q_{6}=0$.

One reach to

$$
\begin{aligned}
& {\left[a+b \cdot\left(i_{r}-i_{\text {bias }}\right)\right] \cdot \sqrt{p_{1}-p_{3 r}}=\left[a-b \cdot\left(i_{r}-i_{\text {bias }}\right)\right] \cdot \sqrt{p_{3 r}-p_{2}}} \\
& {\left[a+b \cdot\left(i_{r}-i_{\text {bias }}\right)\right] \cdot \sqrt{p_{4 r}-p_{2}}=\left[a-b \cdot\left(i_{r}-i_{\text {bias }}\right)\right] \cdot \sqrt{p_{1}-p_{4 r}}}
\end{aligned}
$$

For the stationary regime pressures one may consider

$$
p_{3 r}=\frac{p_{1}+p_{2}}{2}-\Delta p \text { and } p_{4 r}=\frac{p_{1}+p_{2}}{2}+\Delta p
$$

Using although the relation (32) one may determine the pressures $p_{3 r}$ si $p_{4 r}$. Results

$$
p_{3 r}=\left(p_{1}+p_{2}\right) \frac{S_{4}}{S_{3}+S_{4}} \text { and } p_{4 r}=\left(p_{1}+p_{2}\right) \frac{S_{3}}{S_{3}+S_{4}}
$$


Taking account that one used a feeding pressure of 70 bar and the return pressure was negligible, the measured pressures were $p_{3 r}=30.723$ bar and $p_{4 r}=$ 39.277 bar.

From relations (33) and (34) results

$$
\begin{aligned}
& a_{(37)} \cong \frac{b \cdot\left(i_{\text {bias }}-i_{r}\right)\left(\sqrt{p_{1}-p_{3 r}}+\sqrt{p_{3 r}-p_{2}}\right)}{\sqrt{p_{1}-p_{3 r}}-\sqrt{p_{3 r}-p_{2}}}, \\
& a_{(38)} \cong \frac{b \cdot\left(i_{\text {bias }}-i_{r}\right)\left(\sqrt{p_{1}}-p_{4 r}+\sqrt{p_{4 r}-p_{2}}\right)}{\sqrt{p_{4 r}-p_{2}}-\sqrt{p_{1}-p_{4 r}}} .
\end{aligned}
$$

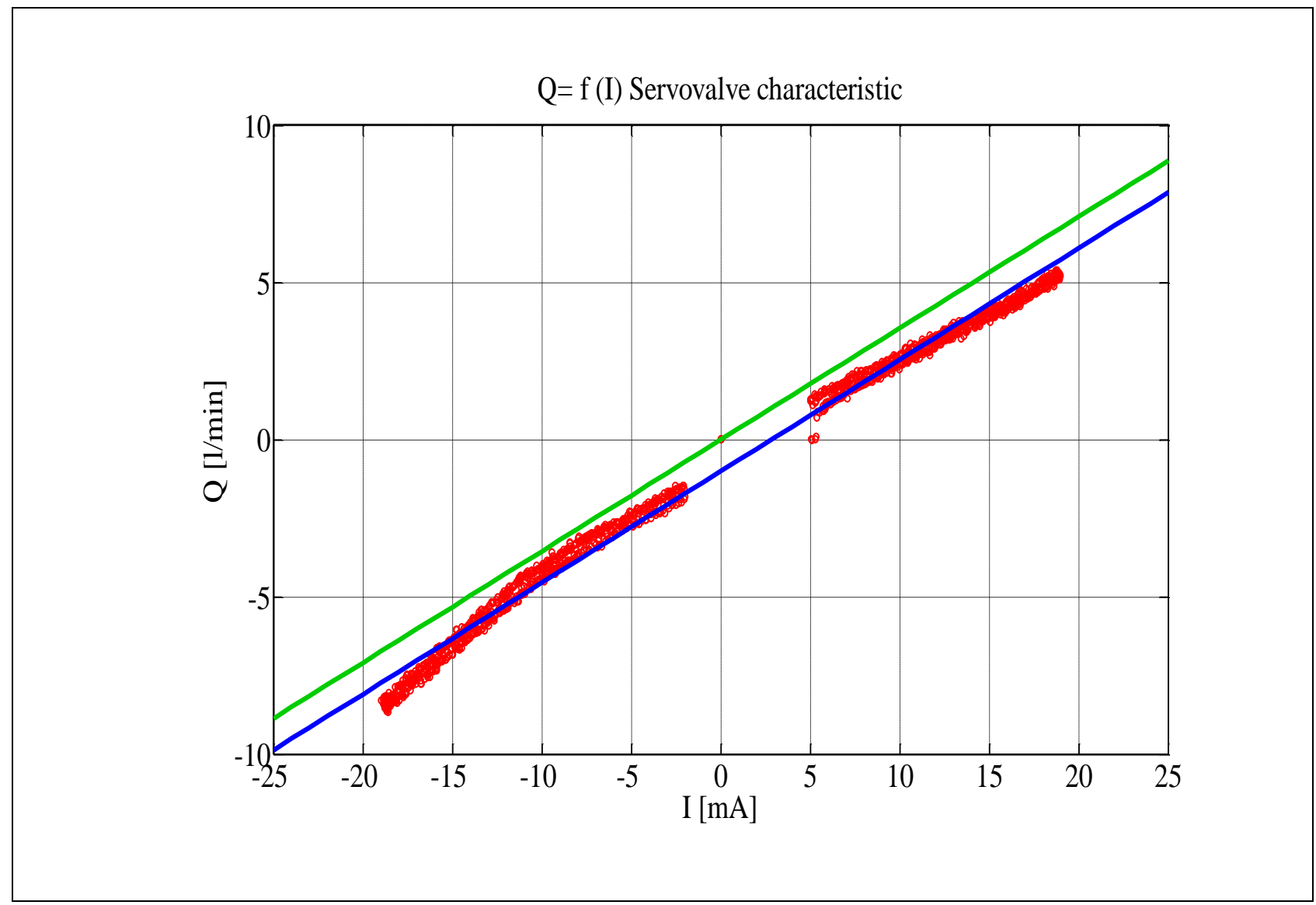

Fig. 7. $Q=f(I)$ corrected characteristic

In figure 8 is presented the command current of the servo-actuator at step input signal when a fuzzy controller was used. This servo-actuator will be presented in the next chapter.

One observe in stationary regime a command current $i_{r}=2,6 \mathrm{~mA}$. Using this value in (37) and (38) and the pressures $p_{3 r}$ and $p_{4 r}$ and the value of parameter $b$ obtained before, results the value $a_{(37 \text { theoretic })}=a_{(38 \text { theoretic })}=0,2221 \mathrm{l} /(\mathrm{min} \cdot \sqrt{\mathrm{bar}})$. 
Servovalve current - fuzzy controller 2

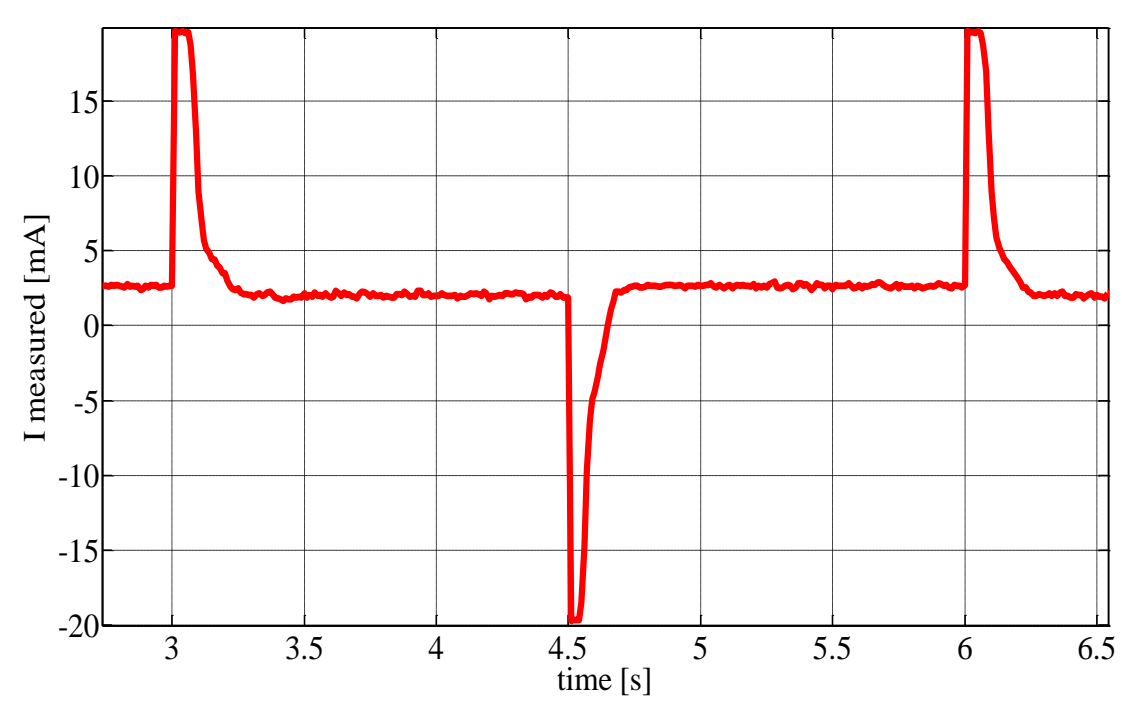

Fig. 8. Servo-actuator command current at step input signal

\section{Experimental Identification of the Hydraulic Resistances $\boldsymbol{R}_{a}$ and $\boldsymbol{R}_{r}$}

In order to complete the identification of the hydraulic bench parameters it is necessary to determine the hydraulic resistances $R_{a}$ and $R_{r}$. These resistances were determined using the pressures $p_{1}-p_{4}$ when the test bench worked in a servo-actuator study. The studied servo-actuator has a proportional controller with the gain $k=10$. In the servo-actuator functioning, at step input signal, one obtained for a relative large interval (about $0.3 \mathrm{~s}$ ) a saturation of the command current of the servo-valve. The command current in these conditions was $\pm 19.5 \mathrm{~mA}$, (one for positive command and one for negative command).

At saturation, one obtains the maximum speed for the piston which can be measured from the time response of the servo-actuator. In this regime the pressure $p_{1}$ drops and $p_{2}$ increases, in conditions of constant pressure at pump. So, measuring the saturation current $i_{s a t}$, the pressures $p_{a}, p_{1}, p_{2}, p_{r}$ and the flow $Q$ one may obtain the resistances $R_{a}$ and $R_{r}$. The flow ratio calculus may be performed using the parameters $a$ and $b$ determined before.

At positive saturation the flows through the servo-valve ports $Q_{5}$ and $Q_{6}$ are given by the relations (15) and (16) and also we have the relations $Q_{a}=Q_{5}$ si $Q_{r}=Q_{6}$. With the bias current result the relations

$$
\begin{aligned}
& Q_{a}=R_{a} \sqrt{p_{a}-p_{1}}=Q_{5}=\left[a+b\left(i_{\text {sat }}^{+}-i_{\text {bias }}\right)\right] \sqrt{p_{1}-p_{3}} \\
& Q_{r}=R_{r} \sqrt{p_{2}-p_{r}}=Q_{6}=\left[a+b\left(i_{\text {sat }}^{+}-i_{\text {bias }}\right)\right] \sqrt{p_{4}-p_{2}} .
\end{aligned}
$$

For negative saturation result $Q_{a}=-Q_{6}$ si $Q_{r}=-Q_{5}$ and also with the bias current one reaches to 


$$
\begin{aligned}
& Q_{a}=R_{a} \sqrt{p_{a}-p_{1}}=-Q_{6}=\left[a-b\left(i_{\text {sat }}^{-}-i_{\text {bias }}\right)\right] \sqrt{p_{1}-p_{4}}, \\
& Q_{r}=R_{r} \sqrt{p_{2}-p_{r}}=-Q_{5}=\left[a-b\left(i_{\text {sat }}^{-}-i_{\text {bias }}\right)\right] \sqrt{p_{3}-p_{2}} .
\end{aligned}
$$

From these relations one find

$$
\begin{aligned}
& R_{a(39)}=\frac{\left[a+b \cdot\left(i_{\text {sat }}^{+}-i_{\text {bias }}\right)\right] \cdot \sqrt{p_{1}-p_{3}}}{\sqrt{p_{a}-p_{1}}} \cdot \frac{1000}{60} \\
& R_{r(40)}=\frac{\left[a+b \cdot\left(i_{\text {sat }}^{+}-i_{\text {bias }}\right)\right] \cdot \sqrt{p_{4}-p_{2}}}{\sqrt{p_{2}-p_{r}}} \cdot \frac{1000}{60}
\end{aligned}
$$

and

$$
\begin{aligned}
& R_{a(41)}=\frac{\left[a-b \cdot\left(i_{\text {sat }}^{-}-i_{\text {bias }}\right)\right] \cdot \sqrt{p_{1}-p_{4}}}{\sqrt{p_{a}-p_{1}}} \cdot \frac{1000}{60} \\
& R_{r(42)}=\frac{\left[a-b \cdot\left(i_{\text {sat }}^{-}-i_{\text {bias }}\right)\right] \cdot \sqrt{p_{3}-p_{2}}}{\sqrt{p_{2}-p_{R}}} \cdot \frac{1000}{60}
\end{aligned}
$$

In relations (43) - (46) the factor 1000/60 is used in order to transform the flow ratios from $1 / \mathrm{min}$ in $\mathrm{cm}^{3} / \mathrm{s}$ so that the obtained hydraulic resistances may be used directly in the numerical simulations of a servo-actuator.

Using the piston speeds in saturation conditions one obtain for positive saturation

$$
\begin{aligned}
& Q_{a}=S_{3} \cdot v_{\text {sat }}^{+} \\
& Q_{r}=S_{4} \cdot v_{\text {sat }}^{+}
\end{aligned}
$$

and for negative saturation

$$
\begin{aligned}
& Q_{a}=S_{4} \cdot v_{s a t}^{-} \\
& Q_{r}=S_{3} \cdot v_{s a t}^{-}
\end{aligned}
$$

From relations (39) - (42) results

$$
\begin{gathered}
R_{a(47)}=\frac{S_{3} \cdot v_{s a t}^{+}}{\sqrt{p_{a}-p_{1}}}, \\
R_{r(48)}=\frac{S_{4} \cdot v_{s a t}^{+}}{\sqrt{p_{2}-p_{r}}}, \\
R_{r(49)}=\frac{S_{4} \cdot v_{s a t}^{+}}{\sqrt{p_{2}-p_{r}}},
\end{gathered}
$$




$$
\begin{aligned}
& R_{a(49)}=\frac{S_{4} \cdot v_{s a t}^{-}}{\sqrt{p_{a}-p_{1}}}, \\
& R_{a(50)}=\frac{S_{3} \cdot v_{s a t}^{-}}{\sqrt{p_{2}-p_{3}}} .
\end{aligned}
$$

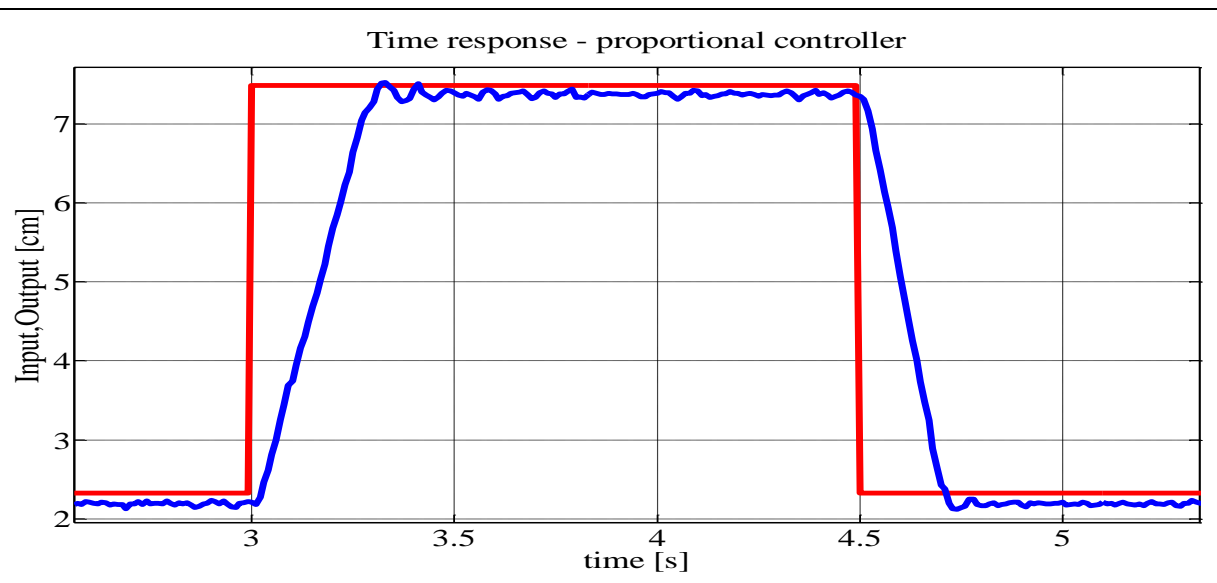

a)

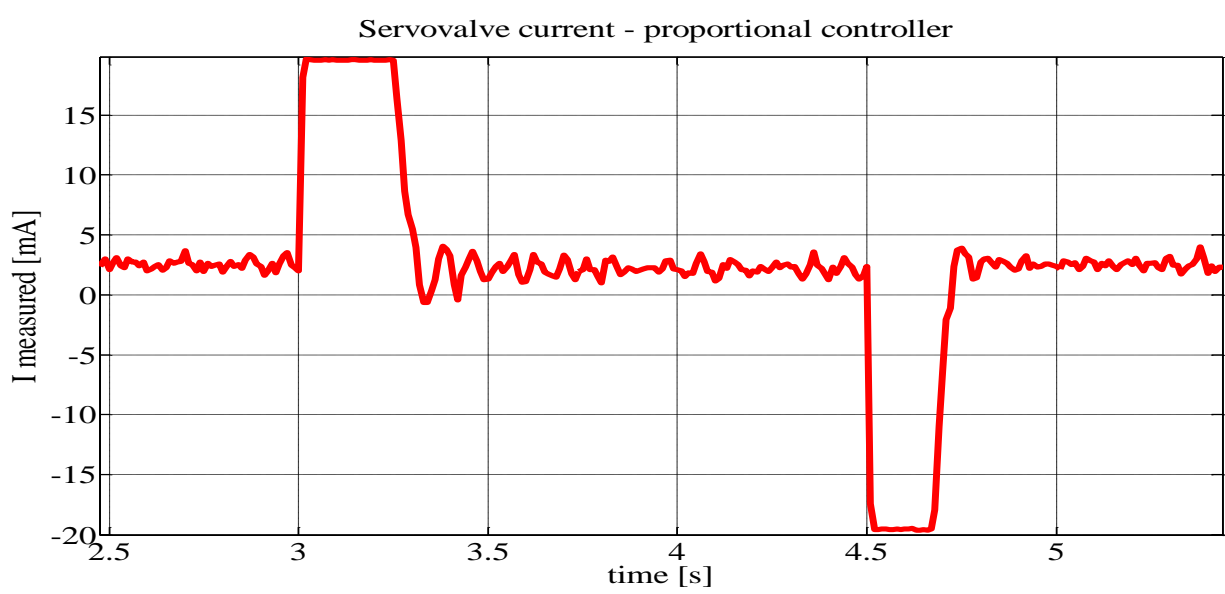

b)

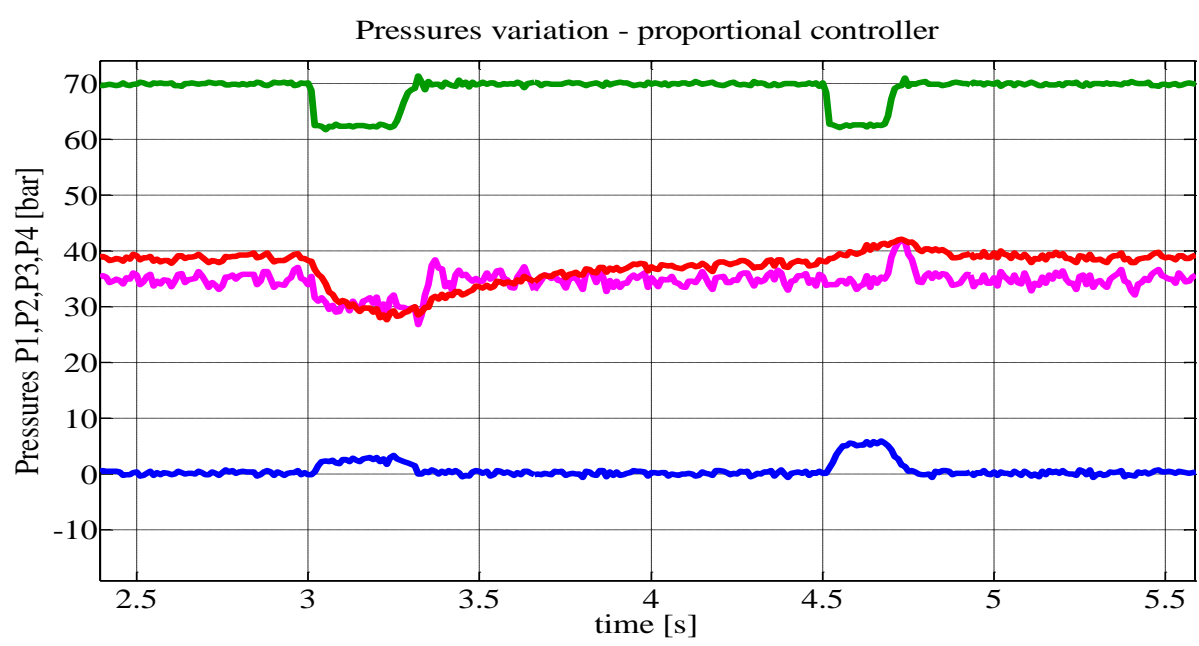

c)

Fig. 9. Time response, command current variation and pressures variations for a servo-actuator with proportional controller with gain $k=10$ 
In figure 9 are presented the time response, the command current and the pressures variations for a servo-actuator with proportional controller with gain $k=10$, using a step input signal.

In figure 9.c in green is presented the pressure $p_{1}$, in blue is pressure $p_{2}$, in magenta is $p_{3}$ and in red is $p_{4}$. For positive saturation one obtained the pressures $p_{1 \text { sat }}^{+}=62.5 \mathrm{bar}, p_{2 \text { sat }}^{+}=2.7 \mathrm{bar}, p_{3 \text { sat }}^{+}=30 \mathrm{bar}$ and $p_{4 \text { sat }}^{+}=30 \mathrm{bar}$, and for negative saturation $p_{1 \text { sat }}^{-}=62.5 \mathrm{bar}, p_{2 s a t}^{-}=5.5 \mathrm{bar}, p_{3 \text { sat }}^{-}=41.5 \mathrm{bar}$ and $p_{4 s a t}^{-}=41.5 \mathrm{bar}$. At positive saturation a displacement between $y=3 \mathrm{~cm}$ and $y=6.5 \mathrm{~cm}$ produced in $0.18 \mathrm{~s}$ and for negative saturation a displacement between $y=6.5 \mathrm{~cm}$ and $y=3 \mathrm{~cm}$ produced in 0.13 s. With these experimental values one obtained the hydraulic resistances

$$
\begin{aligned}
& R_{a(39)}=42.4133 \mathrm{~cm}^{3} /(\mathrm{s} \cdot \sqrt{\mathrm{bar}}), R_{r(40)}=64.7873 \mathrm{~cm}^{3} /(\mathrm{s} \cdot \sqrt{\mathrm{bar}}), R_{a(41)}=48.8802 \mathrm{~cm}^{3} /(\mathrm{s} \cdot \sqrt{\mathrm{bar}}), \\
& R_{r(42)}=63.8687 \mathrm{~cm}^{3} /(\mathrm{s} \cdot \sqrt{\mathrm{bar}}), R_{a(47))}=43.2421 \mathrm{~cm}^{3} /(\mathrm{s} \cdot \sqrt{\mathrm{bar}}), R_{r(48)}=66.5920 \mathrm{~cm}^{3} /(\mathrm{s} \cdot \sqrt{\mathrm{bar}}), \\
& R_{a(49)}=54.2736 \mathrm{~cm}^{3} /(\mathrm{s} \cdot \sqrt{\mathrm{bar}}), R_{r(50)}=81.0230 \mathrm{~cm}^{3} /(\mathrm{s} \cdot \sqrt{\mathrm{bar}}) .
\end{aligned}
$$

One observe the values $R_{a(39)}, R_{a(41)}$ and $R_{a(47)}$ are close enough but a greater deviation presents $R_{a(49)}$. Also, for $R_{r}, R_{r(40)}, R_{r(42)}$ and $R_{r(48)}$ are close enough and a greater deviation presents $R_{r(50)}$. With these values results the medium values $R_{\text {amed }}=47.2298 \mathrm{~cm}^{3} /(\mathrm{s} \cdot \sqrt{\mathrm{bar}})$ and $R_{\text {rmed }}=69.0677 \mathrm{~cm}^{3} /(\mathrm{s} \cdot \sqrt{\mathrm{bar}})$. These values will be used in future works for servo-actuator numerical simulations.

\section{Conclusion}

This paper presents in detail problems concerning the modeling of the servovalves used for electro-hydraulic servo-actuators. It is obtained a simplified mathematical model for the open-center servo-valve and are experimentally determined the parameters involved in this model. These parameters will be used further in the study of electro-hydraulic servo-actuators.

A hydraulic test bench is realized in laboratory for the experimental study of servo-valves and servo- actuators. The servo-valve parameters are identified using one of the hydraulic test bench sections and the servo-actuators will be studied further in the next chapter on a second section of the test bench. The obtained servo-valve characteristic corresponds with the theory presented in literature.

Using the same test bench for servo-valves and servo-actuators encountered although some problems. For the experimental outline of the servo-valve characteristic it was necessary to use a valves bridge in order to ensure the flow sense through the turbine flow transducer. The used valves have an opening pressure about 2-3 bar, so the characteristic $Q=f(I)$ couldn't be obtain near the origin. So, experimentally was obtained only the region for medium and great currents and in this way one could determine the characteristic slope. In order to determine the parameter which describe the behavior of the open center servo-valve it was necessary to use the data obtained from a servo-actuator behavior. The servo-actuator was realized on the same test bench. Finally one obtained an experimental 
characteristic which approximate quite good the servo-valve behavior when it is used in a electro-hydraulic servo-actuator. The experimental data (fig. 6) show although the non-linearity of the experimental characteristic, which usually is neglected in servo-actuators mathematical models. It was identified a bias current which reflect a misadjustment of the servo-valve. This bias current is necessary to be taken account in the servo-actuator modeling. We appreciate it is obtained a good approximation of the servo-valve characteristics which will allow to obtain good results in future experimental and numeric studies for servo-actuators.

The constructive configuration of the test bench implied the use of relative long pipes between the laboratory pump, the test bench and the reservoir. So, these pipes have relative big hydraulic resistances which modify the pressure on the feeding port and the return port of the servo-valve. This situation is consistent with the aircraft hydraulic systems where the distance between the pumps and the servo-actuators may be tens of meters. In order to obtain a more realistic model of the servo-actuators for future studies, one experimentally determined the hydraulic resistances of these pipes. We consider the precision of these results good enough for the future studies.

\section{References}

Borello, L., Vedova M. D., Jacazio G. \& Sorli M. (2009). A Prognostic Model for Electrohydraulic Servovalves. Annual Conference of the Prognostics and Health Management Society

Chen, Q. \& Stoffel, B.( 2004). CFD Simulation of a Hydraulic Servo Valve With Turbulent Flow and Cavitation, ASME/JSME 2004, Pressure Vessels and Piping Conference (PVP2004), San Diego, California, USA

Cheng Guang-Ming, Shen Chuan-liang, \& Yang Zhi-gang. (2006). Experimental Study on the Piezoelectric Prestage Driver of Electrohydraulic Servo Valves. Front. Mech. Eng. China 1: 56-59

Ciupitu, L.; Brotac, S. \& Ivanescu, N. A. (2011). On the Controlling of the Coilers from a Metal Extrusion Press, Annals of DAAAM for 2011 \& Proceedings of the 22nd International DAAAM Symposium, 23-26th November 2011, Vienna, Austria, Volume 22, No. 1, ISSN 1726-9679, ISBN 978-3-901509-83-4, Katalinic, B. (Ed.), pp. 0345-0346, Published by DAAAM International Vienna, Vienna

Dean H. Kim, Tsu-Chin \& Tsao, A. (2000). Linearized Electrohydraulic Servovalve Model for Valve Dynamics Sensitivity Analysis and Control System Design, Journal of Dynamic Systems, Measurement and Control, Volume 122, Issue 1, 179 (9 pages) Dinca, L., Lascu, M., Ivan, M., Budau, I. \& Sarbu, D. (2010). Hydrulic bench for electro-hydraulic servoactuators and servo-valves testing. Annals of University of Craiova, Electrical Engineering Series

Grodić, D., Babić. M. \& Jovičić, N (2004). Modelling of Spool Position Feedback Servovalves, International Journal of Fluid Power, Vol. 5, No. 1, pp. 37 50 
Karunanidhi, S. \& Singaperumal, M. (2010) Design, analysis and simulation of magnetostrictive actuator and its application to high dynamic servo valve, Sensors and Actuators A: Physical,Volume 157, Issue 2, Pages 185-197

Kiliç, A. \& Kapucu, S. (2011). Hidrolik silindir ile sürülen asili yüklerin salinim kontrolü, Ulusal Hidrolik Pnömatik Kongresi 12-15 ekim 2011/Izmir (Hanging loads driven by a hydraulic cylinder oscillation control, the National Congress of Hydraulic and Pneumatic October 12-15 2011/Izmir)

Kim, D. H. \& Tsao, T. C. (2000) Lineariezd Electrohydraulic Servovalve model for Valve Dynamics sensitivity Analysis and Control System Design. ASMEDSMC, Vol.122, pp. 179-187

LI Yong-lin, LI Bao-rui, SHEN Yan-liang \& HU Liang-mou (2009). Thermalhydraulic Modeling and Simulation of Hydraulic Servo Valve, Journal of systems simulation

LIU Xiaochu,YE Zhengmao, HAN Junwei1\& XIAO Lin (2008). Modeling and Simulation of Three-stage Electro-hydraulic Servo Valve Based on AMESim, Machine tool\&hydraulics

Mikhaylov, M.; Larchikov, I. A.; Yurov, A. V.; Cvetkov, V. \& Stazhkov, S. (2011). Hydromechanical Constant Speed Drive Forwind-Driven Generators, Annals of DAAAM for 2011 \& Proceedings of the 22nd International DAAAM Symposium, 2326th November 2011, Vienna, Austria, Volume 22, No. 1, ISSN 1726-9679, ISBN 978-3-901509-83-4, Katalinic, B. (Ed.), pp. 0235-0236, Published by DAAAM International Vienna, Vienna

Prodan, D.; Bucuresteanu, A. M. \& Balan, E. (2011). Heavy Machine-Tools: Modularized Hydraulic Installations, Annals of DAAAM for 2011 \& Proceedings of the 22nd International DAAAM Symposium, 23-26th November 2011, Vienna, Austria, Volume 22, No. 1, ISSN 1726-9679, ISBN 978-3-901509-83-4, Katalinic, B. (Ed.), pp. 0209-0210, Published by DAAAM International Vienna, Vienna

Ruan, J., Ukrainetz P. R. \& Burton, R. (2000). Frequency domain modelling and identification of 2D digital servo valve. International Journal of Fluid Power. Vol. 1, no. 2 , pp. $49-58$

Tao Wang, Maolin Cai, Kenji Kawashima \& Toshiharu Kagawa. (2005). Modelling of a Nozzle-Flapper type Pneumatic Servo Valve including the Influence of Flow Force, International Journal of Fluid Power 6 No. 3 pp. 33-43

Tootell, S.T., Wilson, K. \& Shoptaw, D. (1990) Servo-valve analyzing system and method, - United States Patent no. 4,980,825 - december $25^{\text {th }}$

Urata, E. (1999). Dynamics of elastic structures in servovalve toque motor, Bath Workshop on Power Transmission and Motion Control, (PTMC99). pp. 183-186; YIN Xiaoping,CAO Ming \& LIU Yurong (2008). Fault Simulation Study on Electrohydraulic Servo Valve, Machine tool\&hydraulics, 2008

Zhang, Y., Kagawa, T., Yamamoto, T. \&Nakata, T. ( 2003). Influence of Flow Jet on Nozzle Flapper Systems, Transactions of the Japan fluid power system society, Vol. 34, No. 3. pp 55-61 (in Japanese)

National Instruments Co. - NI-USB 6251 - User Manual - www.ni.com/manuals

National Instruments Co. - LabView - User Manual - www.ni.com/manuals http://www.moog.com/search/?q=servovalve++user+manual\&site 